British Journal of Nutrition (2021), 126, 942-949

doi: $10.1017 /$ S0007114520004857

(C) The Author(s), 2020. Published by Cambridge University Press on behalf of British Journal of Nutrition. This is an Open Access article, distributed under the terms of the Creative Commons Attribution licence (http://creativecommons.org/licenses/by/4.0/), which permits unrestricted re-use, distribution, and reproduction in any medium, provided the original work is properly cited.

\title{
Integration of various dimensions in food-based dietary guidelines via mathematical approaches: report of a DGE/FENS Workshop in Bonn, Germany, 23-24 September 2019
}

Anne Carolin Schäfer ${ }^{1,2 *}$, Annemarie Schmidt ${ }^{1}$, Angela Bechthold ${ }^{1}$, Heiner Boeing ${ }^{3}$, Bernhard Watzl ${ }^{4}$, Nicole Darmon ${ }^{5}$, Brecht Devleesschauwer ${ }^{6,7}$, Thomas Heckelei ${ }^{8}$, Sara Monteiro Pires ${ }^{9}$, Perrine Nadaud ${ }^{10}$, Corné van Dooren ${ }^{11}$ and Florent Vieux ${ }^{12}$

${ }^{1}$ German Nutrition Society, 53175 Bonn, Germany

${ }^{2}$ Department of Nutrition and Food Sciences, Nutritional Epidemiology, University of Bonn, 53012 Bonn, Germany

${ }^{3}$ German Institute of Human Nutrition Potsdam-Rebbruecke, 14558 Nuthetal, Germany

${ }^{4}$ Department of Physiology and Biochemistry of Nutrition, Max Rubner-Institut, 76131 Karlsrube, Germany

${ }^{5}$ MOISA, INRAE, Université Montpellier, 75338 Montpellier, France

${ }^{6}$ Department of Epidemiology and Public Health, Sciensano, 1050 Brussels, Belgium

${ }^{7}$ Department of Veterinary Public Health and Food Safety, Ghent University, 9820 Merelbeke, Belgium

${ }^{8}$ Department of Food and Resource Economics, Economic and Agricultural Policy, University of Bonn, 53012 Bonn, Germany

${ }^{9}$ National Food Institute, Technical University of Denmark, 2800 Lyngby, Denmark

${ }^{10}$ French Agency for Food, Environmental and Occupational Health E Safety, 94701 Maisons-Alfort Cedex, France

${ }^{11}$ Netherlands Nutrition Centre (Voedingscentrum), 2594 The Hague, Netherlands

${ }^{12}$ MS-Nutrition, 13385 Marseille, France

(Submitted 4 August 2020 - Final revision received 18 November 2020 - Accepted 27 November 2020 - First published online 4 December 2020)

\section{Abstract}

In the past, food-based dietary guidelines (FBDGs) were derived nearly exclusively by using systematic reviews on diet-health relationships and translating dietary reference values for nutrient intake into foods. This approach neglects many other implications that dietary recommendations have on society, the economy and environment. In view of pressing challenges, such as climate change and the rising burden of diet-related diseases, the simultaneous integration of evidence-based findings from different dimensions into FBDGs is required. Consequently, mathematical methods and data processing are evolving as powerful tools in nutritional sciences. The possibilities and reasons for the derivation of FBDGs via mathematical approaches were the subject of a joint workshop hosted by the German Nutrition Society (DGE) and the Federation of European Nutrition Societies (FENS) in September 2019 in Bonn, Germany. European scientists were invited to discuss and exchange on the topics of mathematical optimisation for the development of FBDGs and different approaches to integrate various dimensions into FBDGs. We concluded that mathematical optimisation is a suitable tool to formulate FBDGs finding trade-offs between conflicting goals and taking several dimensions into account. We identified a lack of evidence for the extent to which constraints and weights for different dimensions are set and the challenge to compile diverse data that suit the demands of optimisation models. We also found that individualisation via mathematical optimisation is one perspective of FBDGs to increase consumer acceptance, but the application of mathematical optimisation for population-based and individual FBDGs requires more experience and evaluation for further improvements.

Key words: Food-based dietary guidelines: Mathematical optimisation: Diet modelling: Dietary guidelines: Food systems: Sustainability

Food-based dietary guidelines (FBDGs) provide guidance for individuals, health professionals and policy makers on which foods should preferably be consumed in what amounts to maintain good health. In the 1990s, they were considered a major tool of dietary policy by a common initiative of the FAO of the UN and the WHO, which provided scientific considerations in the development of FBDGs ${ }^{(1)}$. The view that population-tailored FBDGs should be issued by all national governments is now well accepted and the basis for public health policies related to foods ${ }^{(2)}$. In the past, such guidance was mainly dominated by

Abbreviations: DALY, disability-adjusted life year; FBDG, food-based dietary guideline.

* Corresponding author: Anne Carolin Schäfer, email schaefer.c@dge.de 
national agricultural and food security policies that took regional and local conditions as a basis for their decisions. This dominance of nutrition policies from the production site has been challenged by a growing scientific discipline which has a strong link to medicine and its branches: nutritional sciences. Through sub-disciplines, such as public health nutrition, nutritional epidemiology and clinical nutrition, the understanding of the relation between dietary intake and health has rapidly grown over the past decades ${ }^{(3,4)}$. Historically, nearly all issued FBDGs were developed by considering the dimensions of nutrient requirements and diet-health relationships ${ }^{(5,6)}$. A good example is the European Food Safety Authority, which considered these two dimensions in their published framework for the scientific process of developing FBDGs for European populations ${ }^{(7)}$. In most cases, this process is based on systematic reviews of current scientific evidence. Background material on this process is not always available. However, transparency of the methodological background and the entire development process is indispensable to underline the scientific base and increase the acceptance of FBDGs within the population as well as with policy makers in the nutrition sector ${ }^{(5)}$.

Nevertheless, nutritional sciences do not only investigate the above-mentioned physical health consequences of dietary intake but also triggered studies on the social, environmental and cultural context of dietary intake and the psychological background $^{(8)}$. The results from this research demand their inclusion in current policies and a shift from a unilateral view to more holistic and interdisciplinary policies. Thus, it is well known that the food system is an important driver of climate change and that transforming the food value chain towards sustainability is an international $\operatorname{aim}^{(9)}$. Various bodies have already linked FBDGs with sustainability and issued so-called sustainable food recommendations ${ }^{(10,11)}$. However, the multidimensional nature of food intake has conceptually not been considered in full to be applied in national FBDGs. Bechthold et al. ${ }^{(5)}$ recently highlighted the frame of such a concept and proposed various dimensions that should be considered in future FBDGs.

One way to integrate different dimensions into FBDGs is provided by emerging methodologies that make use of the advances in mathematics and data processing. In this context, advanced mathematical optimisation methods could deal with a high number of dimensions for which restrictions have been formulated ${ }^{(12,13)}$. These methods have already been applied to find optimal food intakes under specific premises. For example, in the USA optimisation was applied to design consumption bundles closest to recommended dietary patterns for a federal food aid programme, including cost and nutrition constraints ${ }^{(14,15)}$. The FAO derived a tool in order to raise the awareness of low- and middle-income countries to use this kind of approach in the development of their FBDGs ${ }^{(16,17)}$. Dutch and French institutions have also had experience with these methods in preparing background material for their national $\operatorname{FBDGs}^{(18,19)}$. However, there has been little experience with application of dietary data and knowledge regarding the available methods is not widespread among those scientists developing the basis for FBDGs.

In view of the upcoming revision of the current FBDGs for Germany ${ }^{(20)}$, the German Nutrition Society together with the
Federation of European Nutrition Societies organised a workshop on mathematical approaches in nutritional sciences as possible tools for the multidimensional development of FBDGs. The aim was to facilitate the exchange of experts in the field of dietary optimisation and partner organisations that already have or are planning to use such approaches. The Federation of European Nutrition Societies has worked conceptually on the identification of dimensions for future FBDGs ${ }^{(21)}$ and continues to collect stateof-the-art conceptual approaches for modern FBDGs. Therefore, the methodology for the integration of several dimensions into FBDGs from a mathematical perspective is of immense interest.

In this workshop report, we share our insights to support a more harmonised approach between neighbouring countries or regions, in this case Europe. The working group consisted of fifteen participants and included eleven presentations. The participants gathered on 23 and 24 September 2019 in Bonn, Germany, to discuss state-of-the-art methods. For this article, we summarised those presentations that contributed directly to the topic of optimisation and modelling of recommended food intake. The workshop programme can be found in the online Supplementary material.

\section{Dietary optimisation in general}

Dr Nicole Darmon, French National Research Institute for Agriculture, Food and Environment (INRAE), gave an introduction to the topic of diet-related optimisation methods. She asked how nutrient-based recommendations can be translated into food-based practice. One issue addressing this question is that nutrients are not uniformly distributed in foods. The complexity is increased by individual dietary habits and preferences, specific individual needs, aspects of sustainability (indicators such as greenhouse gas emissions, land use, water use and nitrogen loss) and ethical considerations, among others. Calculation tools and integrative databases are needed to address the challenge of integrating various dimensions into FBDGs. Mathematical optimisation tools can help translate nutrient needs into food choices while considering other food-related characteristics, including food safety, bioavailability, budget for food, consumption habits and environmental impact ${ }^{(12)}$. An optimisation model makes the best possible choice towards its objective function within a set of constraints (Fig. 1). The constraints are the requirements that limit the candidate choices, while the objective function determines the best choice among feasible candidates ${ }^{(22)}$.

In principle, these models calculate as tools the optimal intersection of all requirements. Based on food composition tables and the known distribution of food consumption in a population, mathematical optimisation can be used to translate nutrient needs into nutritionally adequate combinations of foods. Diet optimisation can also help to check the applicability of a set of nutrient-based recommendations by testing the mathematical feasibility of simultaneously meeting all the associated constraints: this was done in 2001 for the French dietary reference values $^{(23)}$. Another example of using such tools is to calculate the minimal cost required for fulfilling all nutrient-based recommendations ${ }^{(24)}$, and studies show that the minimal cost of a nutritionally adequate diet rises with increasing respect for food habit patterns ${ }^{(25)}$. 


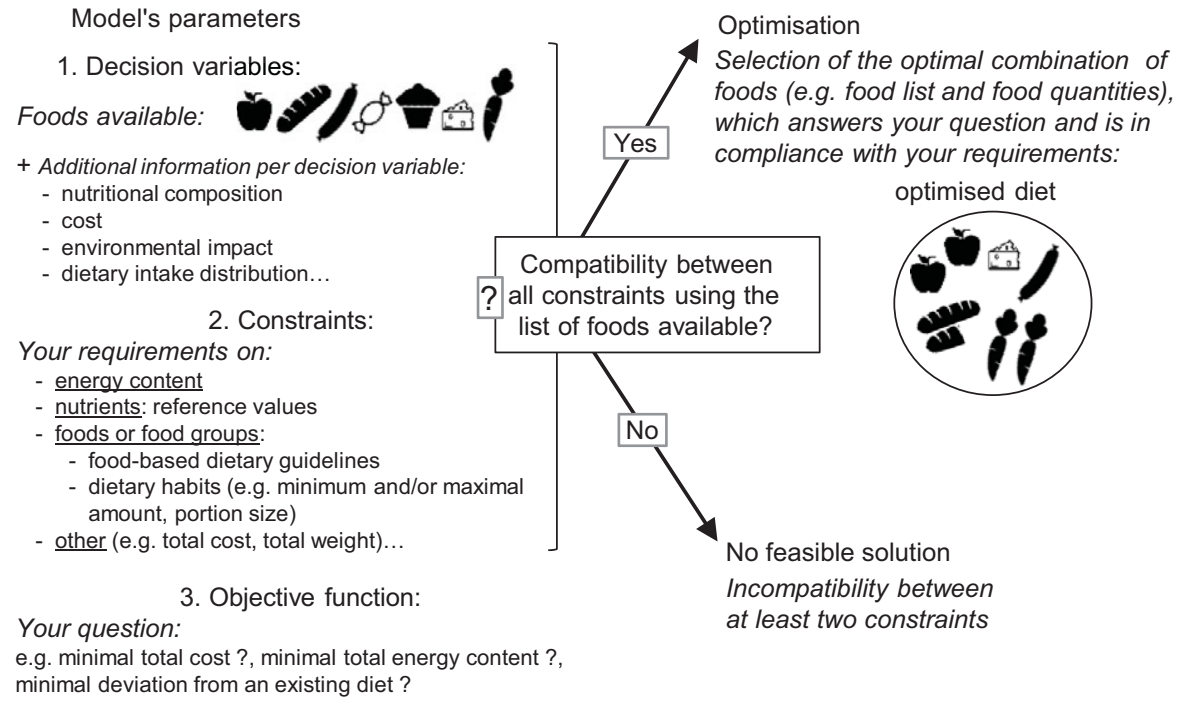

Fig. 1. Principle of mathematical optimisation of diets. With permission from Gazan et al. ${ }^{(12)}$.

One major dimension to be included is the environmental aspect of diets. Nicole Darmon pointed out the four dimensions of sustainable diets: health, environment, economy and culture $^{(26)}$. Based on the heterogeneity of these facets with their different metrics (such as nutrients, costs or consumption in $\mathrm{g} / \mathrm{d}$ ) and food groupings, their integration into one model creates a complex process. There are also specific individual needs, such as diseases, allergies or the varying genetic backgrounds of people. Furthermore, it is beneficial to customise diets to food habits and preferences, the financial budget, and to social, environmental as well as ethical considerations. Mathematical approaches can support the derivation of diets, because they are able to handle conflicting data that would be too much to be surveyed by a person, but a person will set the framework within which the mathematical approach has to work. The aggregation of data from heterogeneous sources is one challenge to face. Gazan et al. ${ }^{(27)}$ developed a methodology to compile multiple metrics of foods into one single database. Taken together, mathematical optimisation is a powerful tool to translate multidimensional information on individual foods into healthy and sustainable diets ${ }^{(12)}$.

\section{European experience in derivation of food-based dietary} guidelines via optimisation

Dr Ir Corné van Dooren, Netherlands Nutrition Centre, put emphasis on the integration of sustainability into dietary recommendations. Sustainable diets are defined as nutritionally adequate, safe and healthy ${ }^{(26)}$. The Dutch optimisation approach tries to integrate sustainability into FBDGs using the linear and quadratic programming model Optimeal for the simultaneous optimisation of natural and human resources: diet, nutrients, economy and environment. Compared with the Mediterranean diet, the Nordic diet, the flexitarian diet and the pesco-vegetarian diet, the optimised traditional Dutch diet ('Low Lands Diet') is similarly healthy but more sustainable in terms of greenhouse gas emissions and land use ${ }^{(28)}$, which were the indicators chosen to measure ecological sustainability. The same optimisation model was used to develop the Dutch 2015 FBDGs, using environmental constraints limiting the quantities of animal-based products $^{(19)}$.

In order to achieve compliance with FBDGs, it is important to take people's dietary habits into account. For the current Dutch FBDGs, the optimisation model had the objective to minimise the deviation from current food consumption. Mathematical optimisation models often ensure a palatable and culturally acceptable diet by implementing it as the objective function, as done in the Dutch FBDGs. Introducing acceptability constraints is recommended, but no study has provided the ultimate solution for the calculation of constraints, which measure to what extent a diet shall be allowed to differ from the actual intake to satisfy the consumer ${ }^{(29)}$. Constraints were set for food and nutrient intake. The health aspect was mostly the reason for minimum and maximum amounts in certain food groups. Health, environmental and feasibility aspects were chosen as maximum quantity constraints for animal-based food groups.

Most optimisation studies have used nutrition and cost constraints in the analysis of dietary problems and solutions, and recently twelve studies applied ecological constraints. However, such research begins to show weaknesses in situations featuring a small number of food items and/or nutritional constraints. Optimisation is able to suggest diets with lower projected environmental impacts than the impacts of diets assessed through scenario type studies, where diets are predetermined ${ }^{(29)}$. One of the studies that examined diets derived by linear programming found out that using ecological and cost constraints would not result in diets with a higher cost, but rather these diets could be even more affordable $\mathrm{e}^{(30)}$.

The Netherlands Nutrition Centre (Voedingscentrum) strives to inform people to make healthier and more sustainable foods choices. The development of the 2016 Dutch FBDGs, represented as the food guide 'Wheel of Five', results in the reduction of greenhouse gas emissions for most consumers. Thus, by more often choosing vegetarian days and more sustainable options within food groups, greenhouse gas emissions can be reduced 
7$$
6
$$

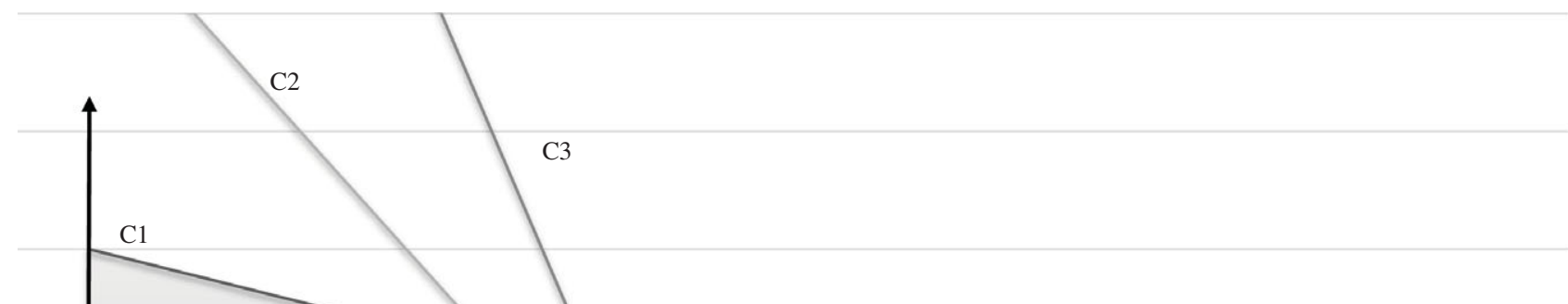

4

3

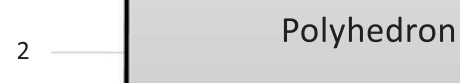

0

$-1$

Fig. 2. Linear programming as a graph in a simplified model.

by one-third compared with the current average Dutch diet ${ }^{(31)}$. Corné van Dooren concluded that sustainable diets can simultaneously be nutritionally adequate, safe and healthy as shown in the derivation of the Dutch FBDGs. Mathematical optimisation as a tool supported the development process of these guidelines.

Perrine Nadaud, French Agency for Food, Environmental and Occupational Health \& Safety, explained the French optimisation approach published in 2016. It included several aspects, such as dietary reference values, food-borne contaminants, bioavailability, prevention of chronic diseases and others. A linear programming of combined models (Simplex method) was applied to calculate the optimal consumption for each food group. The optimisation criteria were classified into (a) disease prevention, for example, minimising consumption of red meat, (b) contaminant exposure, for example, minimising the exposure to certain food contaminants and (c) eating habits, aiming to minimise deviations from the current consumption. The Simplex model's algorithm helped to determine a target value by successive iterations on one or more variables, taking into account the constraints imposed. If the model did not find a solution within these several constraints, the breach of contaminant and nutritional constraints was minimised. The model searched for the only optimal solution in the domain of possible ones, corresponding to a polyhedron with $N$ dimensions defined by the constraints (Fig. 2). The blue area (polyhedron) defines the possible solutions, while $\mathrm{C} 1-3$ are the straights showing the constraints. The French approach included a series of optimisation scenarios, where more and more features were added. The constraints were adjusted or relaxed to make compromises for the feasibility of the diet.
Perrine Nadaud outlined the advantages of this approach, which include that it is a global and transposable method that allows defining science-based FBDGs and identifying public health issues. Still, there are limitations to this approach. Uncertainties from the original database are transferred to the optimisation database. Often, the bioavailability of nutrients is not considered. The perspective is to extend the method to different subgroups and different dietary patterns and to weigh the criteria for the optimisation ${ }^{(18)}$. In the future, the French agency wishes to implement environmental impact. Indeed, another advantage of this method is that new dimensions can be added to obtain more comprehensive results without having to redo all the work.

\section{Building the optimisation model's database:} mathematical approaches to calculate data for diet-health relations and sustainability

To run an optimisation model, a database containing data regarding the chosen food groups has to be built. Therefore, data for the various dimensions need to be collected or calculated. For diet-health relationships, Dr Brecht Devleesschauwer, Sciensano and Ghent University, held a presentation on the assessment of health impacts of foods.

Disability-adjusted life years (DALYs) summarise different parameters of population health for a certain disease in a single metric. They quantify the gap between an ideal life in perfect health and ideal life expectancy on the one hand, and reality with diseases and early deaths on the other hand. Using comparative 
risk assessment, it is possible to calculate the fraction of DALYs, which is attributable to a certain risk factor, and thereby rank different risk factors according to their health impact ${ }^{(32)}$. These risk factors can be defined as dietary risk factors, such as 'diet low in fruit'. For the definition of a diet low in certain foods, optimal consumption levels of foods are to be determined ${ }^{(33)}$. For the derivation of FBDGs, the DALYs linked to consumption levels of certain foods in different countries may be used as a source for the optimisation database. In this way, the burden of disease may support the development of future FBDGs. DALYs for diethealth relationships may furthermore be combined with DALYs for food safety. Nevertheless, this approach remains focused on the health impact, while for the derivation of FBDGs additional dimensions, such as sustainability, matter.

One possibility to assess the sustainability of diets is to use agri-environmental modelling. Professor Thomas Heckelei, University of Bonn, presented the steps the SUSFANS project (Metrics, Models and Foresight for European SUStainable Food And Nutrition Security, 2015-2019) took towards this goal. SUSFANS is a project coupling the models SHARP (Sustainable, Healthy, Affordable, Reliable and Preferred diets), which derives sustainable, healthy, affordable, reliable and preferred diets ${ }^{(34,35)}$, and MAGNET (Modular Applied GeNeral Equilibrium Tool), which simulates the impacts of agricultural, trade, land and bioenergy policies on the global economy ${ }^{(36)}$. Coupling SHARP and MAGNET generally allows analysts to assess the dietary consequences of changes in political or economic conditions. This also links diets to the sustainability of food production to the extent by which the economic model provides environmental indicators related to food production activities. Still, remaining challenges need to be tackled. One challenge lies in the (dis-)aggregation of data. Compared with typical diet data, food categories in economic models are quite aggregated. Thomas Heckelei stated that the remaining challenges are to implement such mappings also for other agrienvironmental models (CAPRI and GLOBIOM (Global Biosphere Management Model)), which offer a closer link of diets to sustainability metrics, and to harmonise the sustainability metrics currently used in diet and economic models.

When we discussed the economic dimension of nutrition in terms of FBDGs, the consumers were identified as one important factor. Their preferences and eating behaviours are often integrated via dietary intake data. The impact of changing circumstances (like raised taxes on certain foods) on the consumer's dietary habits is missing so far at the required level of detail. Another application of SUSFANS assessed the impacts of European Union's food tax policy on nutrition and environmental sustainability. Three scenarios were simulated for the year 2050: tax on calories, tax on food groups and the combination of calories' and food groups' tax. The results show that the taxes necessary to achieve dietary recommendations for the average consumer considering current eating preferences would have to increase food prices considerably ${ }^{(37)}$. The proportion of the dietary intake across the population of each European country is not captured by the current implementation. This would require obtaining food intake data representative of a whole country and in addition of comparable quality for all of Europe. If, in addition, the economic models would be extended to capture the heterogeneous food consumption behaviour across population groups, a significant improvement of the link between food system sustainability and food-related health problems would be achieved.

\section{Application of diet optimisation for individuals}

Another possibility to include consumer decisions in dietary recommendations is to calculate personalised FBDGs. The difference between population-based and individual-based diet optimisation is that for the population several individual diets are aggregated to represent one average diet, which is optimised and the outcome is also one optimal diet. In contrast, for individuals, every single diet is optimised and results in one optimised diet for each individual. Minimising the deviations from the individual's current diet increases acceptability of changes in the consumer's eating behaviour. While individual-based diet optimisation was applied to food consumption data from national dietary surveys to understand dietary changes capable of improving nutritional intake in a given population ${ }^{(38-43)}$, MS-Nutrition company, in collaboration with INRAE, has developed an approach in order to use it in real life ${ }^{(44,45)}$. The fact that the consumer is aware of the uniqueness of his/her personal nutrition advice adds to the advantages of personalised FBDGs ${ }^{(46,47)}$. Moreover, the user is the director of his/her own dietary changes by selecting diet suggestions achievable from the individual's point of view ${ }^{(44)}$. This promising tool still requires qualitative and quantitative evaluation for further improvements.

Dr Florent Vieux, MS-Nutrition, gave an overview of his work at a start-up regarding the developing innovative operational research methods (based on statistics, simulation and optimisation) to evaluate and improve food offer and food choices' quality. MS-Nutrition offers modelling and statistics expertise in nutrition research projects. The company facilitates quantitative nutrition, which allows estimating and improving the nutritional quality of foods, menus and diets. MS-Nutrition participated in the development of an FAO diet optimisation package for low- and middle-income countries' FBDGs ${ }^{(17)}$. The company is now testing the possibility of applying diet optimisation on the FAO/WHO GIFT (Global Individual Food consumption data Tool) platform data with the idea of developing a populationbased diet optimisation web app based on data provided by the platform. The user needs to select the population, set the constraints and the objective function and run the optimisation. The results are the dietary changes suggested by the optimisation model. Ultimately, the model can demonstrate to the user how far the food groups contribute to the nutrients in the observed and optimised diet

\section{Application of diet optimisation for risk-benefit assessment}

In addition to FBDGs, mathematical optimisation can be applied to other cases of nutritional sciences as was explained by Dr Sara Monteiro Pires, Technical University of Denmark. When it comes to FBDGs, the beneficial and adverse effects of foods and dietary patterns, as well as the current preferences of the population 
should be taken into account. Risk-benefit assessment of foods is an established tool that considers nutrition, toxicology, microbiology and epidemiology. A classic example that Sara Monteiro Pires' working group has been investigating is fish: here, the benefits of EPA and DHA, as well as the risks of methyl mercury and dioxins are present at the same time. In the process of the riskbenefit assessment, the beneficial as well as adverse effects are identified, characterised and the exposure is assessed (e.g. via food intake). In the next step, they are integrated into a scenario comparison $^{(48)}$. Insufficient intake can lead to a risk of inadequate nutrition due to the lack of nutrients, while excessive intake can lead to the risk of toxicity due to an overdose of nutrients/contaminants.

The recommendation 'Eat more fish', specifically $350 \mathrm{~g}$ per week, is part of the Danish FBDGs ${ }^{(49)}$. Only $15 \%$ of the Danish population meet the fish guideline. To bridge the gap between recommended fish intake and observed fish intake in Denmark, Sara Monteiro Pires' group developed an optimisation model and fed it with food consumption data, constraints and individual data on observed fish intakes and body weights. They derived personalised fish intake recommendations via a quadratic programming model. The model had constraints for nutrients and contaminants, while striving to minimise the deviation from personal fish consumption preferences ${ }^{(50)}$. The aim was to provide evidence to eventually redefine FBDGs, by considering individual variations as well as risks and benefits of foods with the goal of increased compliance with FBDGs. In another case study, the economical dimension with price as the indicator was integrated into the optimisation model. This showed that it is possible to minimise the deviation from fish intakes and cost simultaneously. The constraints stayed the same ${ }^{(51)}$.

The comparison of risks and benefits can also be performed using a composite health metric like DALYs. The assessment can be performed by calculating the changes in incidence due to changed exposure. A study in the Danish population estimated that different consumption scenarios of the substitution of red meat with fish led to diverse health gains or losses at the population level ${ }^{(52)}$.

Sara Monteiro Pires concluded that modelling approaches can improve FBDGs: they account for beneficial and adverse health effects of foods and diets, for the impact of substituting one food for another/different combinations and for individual preferences and characteristics. She also stressed the importance of personalised advice ${ }^{(53-55)}$

\section{Workshop conclusions}

In general, mathematical optimisation was acknowledged by the workshop participants as a versatile multi-criteria method to answer contrasting and complex questions in nutritional sciences. The approaches from the Netherlands and France show that it seems to be a suitable method to derive FBDGs that are based on scientific evidence from several dimensions with conflicting as well as aligning goals. Furthermore, the use of mathematical optimisation can support the objectivity and transparency of approaches to develop FBDGs, when the decisions made in the optimisation models, the list of constraints and the equation of the objective function are clearly stated and described, helping to create comprehensive background material on the development of FBDGs. Another perspective is that individualisation of FBDGs, enabled by mathematical optimisation, could help to improve consumer acceptance of FBDGs, increasing the proximity to their personal current diet.

Still, there are specific limitations of mathematical optimisation as a tool to derive FBDGs. For the implementation in FBDGs, this is a relatively new scientific research field with few restrictions on the method itself, but little experience and no evidence on specific aspects: decisions, such as weighting of the dimensions in the objective function and setting the constraints and their range, for example, the deviation from the current diet, are up to the developer and/or the user and may be carefully selected by an expert panel. One subjective decision may already be, which dimensions should be integrated at all. Another challenge is to operationalise the dimensions in order to apply nutritional sciences data (that has been derived from information on whole foods instead of nutrients) and translate them into FBDGs as well as to create one database with information on the various dimensions coming from different sources, heterogeneous methodologies and differing food grouping systems. One example is that diet-health relations, which were integrated as constraints up to now, need a derivation of the amounts beforehand. To move this area forward, a metric for diet-health relations would be needed. Moreover, the harmonisation of food grouping systems is desirable to avoid loss of information in the food mapping process. For FBDG groups, a strong link to dietary intake data is needed. The food grouping system FoodEx 2 by the European Food Safety Authority is the basis for several dietary intake studies and was found to be suitable to be used for FBDGs. Another advantage is its hierarchical system, which makes it possible to calculate missing values from one hierarchical level to another. Data acquisition in FoodEx2 would help FBDG makers to use it directly.

The workshop participants discussed the complex demands in the formulation of FBDGs, with emphasis on the transformation of the food system. Therefore, the future derivation of FBDGs should take into account a larger number of relevant dimensions, such as those related to sustainability. In view of improving data sources and evolving mathematical methods and data processing, we strive to raise awareness of the use of mathematical approaches, especially mathematical optimisation methods, in nutritional sciences. The European scientists attending the workshop agreed that mathematical optimisation is a useful tool that should be advanced jointly to derive FBDGs and tackle public health issues.

\section{Acknowledgements}

The German Nutrition Society and the Federation of European Nutrition Societies are very pleased to have had this intensive exchange with our colleagues from Europe. The workshop was a starting point for an international cooperation and joint further development of a new scientific concept for deriving FBDGs. We thank all presenters and participants for their contributions. 
Workshop participants: Arnesen, Erik; Bala, Malgorzata; Bechthold, Angela; Boeing, Heiner; Darmon, Nicole; Devleesschauwer, Brecht; Heckelei, Thomas; Heseker, Helmut; Kroke, Anja; Monteiro Pires, Sara; Nadaud, Perrine; Schäfer, Anne Carolin; Schmidt, Annemarie; Van Dooren, Corné; Vieux, Florent.

The authors thank Heike Norman, Max-Rubner-Institut, for her careful language editing.

The workshop was funded by the Federation of European Nutrition Societies and the German Nutrition Society.

A. C. S., A. S. and H. B. drafted a first version and all authors contributed with revisions and improvements into the final manuscript that was approved by all authors.

The authors declare that they have no conflict of interest.

\section{Supplementary material}

For supplementary material referred to in this article, please visit https://doi.org/10.1017/S0007114520004857

\section{References}

1. Food and Agriculture Organization \& World Health Organization (1998) Preparation and Use of Food-Based Dietary Guidelines. Report of a joint FAO/WHO consultation, Nicosia, Cyprus. Geneva: World Health Organization.

2. Herforth A, Arimond M, Álvarez-Sánchez C, et al. (2019) A global review of food-based dietary guidelines. Adv Nutr 10, 590-605.

3. Byers T (1999) The role of epidemiology in developing nutritional recommendations: past, present, and future. Am J Clin Nutr 69, 1304S-1308S.

4. Satija A, Yu E, Willett WC, et al. (2015) Understanding nutritional epidemiology and its role in policy. Adv Nutr 6, 5-18.

5. Bechthold A, Boeing H, Tetens I, et al. (2018) Perspective: food-based dietary guidelines in Europe-scientific concepts, current status, and perspectives. Adv Nutr 9, 544-560.

6. Wijesinha-Bettoni R, Khosravi A, Sherman J, et al. (2017) Implementing food-based dietary guidelines for policies, programmes, nutrition education. Action Area 5: safe, supportive environments for nutrition at all ages. UNSCN News, no. 42, 77-89.

7. EFSA (European Food Safety Authority) (2010) Scientific opinion on establishing food-based dietary guidelines. EFSA J 8, 1460.

8. Nordström K, Coff C, Jönsson H, et al. (2013) Food and health: individual, cultural, or scientific matters?. Genes Nutr $8,357-363$.

9. United Nations, Department of Economic and Social Affairs (2015) Transforming our world: The 2030 Agenda for sustainable development. https://sdgs.un.org/2030agenda (accessed July 2020).

10. Gonzalez Fischer C \& Garnett T (2016) Plates, pyramids, planet: developments in national healthy and sustainable dietary guidelines: a state of play assessment. http://www.fao.org/ documents/card/en/c/d8dfeaf1-f859-4191-954f-e8e1388cd0b7/ (accessed May 2019).

11. Rose D, Heller MC \& Roberto CA (2019) Position of the Society for Nutrition Education and Behavior: the importance of including environmental sustainability in dietary guidance. $\mathrm{J} \mathrm{Nutr}$ Educ Behav 51, 3-15.e1.

12. Gazan R, Brouzes CMC, Vieux F, et al. (2018) Mathematical optimization to explore tomorrow's sustainable diets: a narrative review. Adv Nutr 9, 602-616.
13. Hernández M, Gómez T, Delgado-Antequera L, et al. (2019) Using multiobjective optimization models to establish healthy diets in Spain following Mediterranean standards. Oper Res Int J 14, 2274.

14. Wilde PE \& Llobrera J (2009) Using the thrifty food plan to assess the cost of a nutritious diet. J Consumer Affairs $\mathbf{4 3}$, 274-304.

15. Babb AM, Knudsen DC \& Robeson SM (2019) A critique of the objective function utilized in calculating the Thrifty Food Plan. PLOS ONE 14, e0219895.

16. FAO (Food and Agriculture Organization of the United Nations) (2019) Food-based dietary guidelines. Third webinar: Diet modelling for food-based dietary guidelines. http://www. fao.org/nutrition/education/food-dietary-guidelines/capacitydevelopment/webinar-series/third-webinar/en/ (accessed October 2020).

17. FAO (Food and Agriculture Organization of the United Nations) (2019) Webinar: Diet modelling in the development of food-based dietary guidelines. http://www.fao.org/fsnforum/ news/webinar-diet-modelling-development-food-based-dietaryguidelines (accessed June 2020).

18. French Agency for Food, Environmental and Occupational Health \& Safety (2016) Updating of the PNNS guidelines: revision of the food-based dietary guidelines. Request No 2012-SA-0103. https://www.anses.fr/en/system/files/NUT2012SA0103Ra-1EN. pdf (accessed July 2019).

19. Brink E, van Rossum C, Postma-Smeets A, et al. (2019) Development of healthy and sustainable food-based dietary guidelines for the Netherlands. Public Health Nutr 22, 2419-2435.

20. Jungvogel A, Michel M, Bechthold A, et al. (2016) Die lebensmittelbezogenen Ernährungsempfehlungen der DGE. Wissenschaftliche Ableitung und praktische Anwendung der Modelle (The food-related nutritional recommendations of the DGE. Scientific derivation and practical application of the models). Ernährungs Umschau 63, M474-M481.

21. Tetens I, Birt CA, Boeing H, et al. (2020) Food-Based Dietary Guidelines - development of a conceptual framework for future food based dietary guidelines in Europe. Report of a FENS Task-Force workshop in Copenhagen, 12-13 March 2018. Br J Nutr 124, 1338-1344.

22. Boyd S \& Vandenberghe L (2009) Convex Optimization, 7th ed. Cambridge: Cambridge University Press.

23. Martin A (2001) The "apports nutritionnels conseillés (ANC)" for the French population. Reprod Nutr Dev 41, 119-128.

24. Darmon N, Ferguson EL \& Briend A (2006) Impact of a cost constraint on nutritionally adequate food choices for French women: an analysis by linear programming. $J$ Nutr Educ Behav 38, 82-90.

25. Maillot M, Darmon N \& Drewnowski A (2010) Are the lowestcost healthful food plans culturally and socially acceptable? Public Health Nutr 13, 1178-1185.

26. Burlingame B \& Dernini S (2012) Sustainable diets and biodiversity - Directions and solutions for policy research and action: Proceedings of the International Scientific Symposium Biodiversity and Sustainable Diets United Against Hunger. http://www.fao.org/3/a-i3004e.pdf (accessed May 2019).

27. Gazan R, Barré T, Perignon M, et al. (2016) A methodology to compile food metrics related to diet sustainability into a single food database: application to the French case. Food Chem 238, $125-133$.

28. van Dooren C \& Aiking H (2016) Defining a nutritionally healthy, environmentally friendly, and culturally acceptable Low Lands Diet. Int J Life Cycle Assess 21, 688-700.

29. van Dooren C (2018) A review of the use of linear programming to optimize diets, nutritiously, economically and environmentally. Front Nutr 5, 48. 
30. van Dooren C, Tyszler M, Kramer G, et al. (2015) Combining low price, low climate impact and high nutritional value in one shopping basket through diet optimization by linear programming. Sustainability 7, 12837-12855.

31. van de Kamp ME, van Dooren C, Hollander A, et al. (2018) Healthy diets with reduced environmental impact? - the greenhouse gas emissions of various diets adhering to the Dutch food based dietary guidelines. Food Res Int 104, 14-24.

32. Schwingshackl L, Knüppel S, Michels N, et al. (2019) Intake of 12 food groups and disability-adjusted life years from coronary heart disease, stroke, type 2 diabetes, and colorectal cancer in 16 European countries. Eur J Epidemiol 34, 765-775.

33. GBD 2017 Diet Collaborators (2019) Health effects of dietary risks in 195 countries, 1990-2017: a systematic analysis for the Global Burden of Disease Study 2017. Lancet 393, 1958-1972.

34. Mertens E, Kaptijn G, Kuijsten A, et al. (2019) SHARP-indicators database towards a public database for environmental sustainability. Data Brief 27, 104617.

35. Mertens E, Kuijsten A, van Zanten HH, et al. (2019) Dietary choices and environmental impact in four European countries. J Clean Prod 237, 117827

36. Kuiper M \& Zurek M (2017) Deliverable 1.4: A modelling strategy for quantifying the sustainability of food and nutrition security in the EU. https://susfans.eu/portfolio/modellingstrategy-quantifying-sustainability-food-and-nutrition-securityeu (accessed January 2020)

37. Latka C, Kuiper M, Frank S, et al. (2021) Paying the price for environmentally sustainable, healthy EU diets. Glob Food Sec 28, 100437.

38. Maillot M, Vieux F, Amiot MJ, et al. (2010) Individual diet modeling translates nutrient recommendations into realistic and individual-specific food choices. Am J Clin Nutr 91, 421-430.

39. Lluch A, Maillot M, Gazan R, et al. (2017) Individual diet modeling shows how to balance the diet of French adults with or without excessive free sugar intakes. Nutrients $\mathbf{9}, 2$

40. Maillot M, Vieux F, Ferguson EF, et al. (2009) To meet nutrient recommendations, most French adults need to expand their habitual food repertoire. J Nutr 139, 1721-1727.

41. Maillot M, Vieux F, Delaere F, et al. (2017) Dietary changes needed to reach nutritional adequacy without increasing diet cost according to income: an analysis among French adults. PLOS ONE 12, e0174679.

42. Vieux F, Brouzes C, Maillot M, et al. (2016) Role of young child formulae and supplements to ensure nutritional adequacy in U.K. young children. Nutrients $\mathbf{8}, 539$.
43. Horgan GW, Perrin A, Whybrow S, et al. (2016) Achieving dietary recommendations and reducing greenhouse gas emissions: modelling diets to minimise the change from current intakes. Int J Behav Nutr Phys Act 13, 46.

44. Gazan R, Darmon ND, Vieux FV, et al. (2019) MS-Diet, a tailored nutrition counselling web-application based on mathematical diet optimization. Eur J Public Health 29, Suppl. 4, ckz185.096.

45. Gazan R (2018) Développement d'une approche de prévention nutritionnelle sur-mesure à destination des individus, prenant en compte différentes dimensions de l'alimentation durable (Development of a tailor-made nutritional prevention approach for individuals, taking into account different dimensions of sustainable food). PhD thesis, Montpellier.

46. Kreuter MW \& Skinner CS (2000) Tailoring: what's in a name? Health Educ Res 15, 1-4.

47. Kreuter MW, Strecher VJ, Glassman B, et al. (1999) One size does not fit all: the case for tailoring print materials. Ann Behav Med 21, 276-283.

48. Tijhuis MJ, Jong N de, Pohjola MV, et al. (2012) State of the art in benefit-risk analysis: food and nutrition. Food Chem Toxicol 50, $5-25$.

49. Ministeriet for Fødevarer, Landbrug og FiskeriFødevarestyrelsen (2013) De officielle Kostråd (Official Dietary Guidelines), 1st ed. Glostrup: Ministeriet for Fødevarer, Landbrug og FiskeriFødevarestyrelsen.

50. Persson M, Fagt S, Pires SM, et al. (2018) Use of mathematical optimization models to derive healthy and safe fish intake. J Nutr 148, 275-284.

51. Persson M, Fagt S \& Nauta MJ (2019) Optimizing healthy and safe fish intake recommendations: a trade-off between personal preference and cost. Br J Nutr 122, 206-219.

52. Thomsen ST, Boer W, Pires SM, et al. (2019) A probabilistic approach for risk-benefit assessment of food substitutions: a case study on substituting meat by fish. Food Chem Toxicol 126, 79-96.

53. Celis-Morales C, Livingstone KM, Marsaux CF, et al. (2017) Effect of personalized nutrition on health-related behaviour change: evidence from the Food4me European randomized controlled trial. Int J Epidemiol 46, 578-588.

54. Brug J, Campbell M \& van Assema P (1999) The application and impact of computer-generated personalized nutrition education: a review of the literature. Patient Educ Couns 36, 145-156.

55. Brug J, Oenema A \& Campbell M (2003) Past, present, and future of computer-tailored nutrition education. Am J Clin Nutr 77, Suppl. 4, 1028S-1034S. 